\title{
Ultraviolet absorbance of Sphagnum magellanicum, S. fallax and S. fuscum extracts with seasonal and species-specific variation
}

\author{
$J_{\text {. Tienaho }}{ }^{1}$ N. Silvan ${ }^{1} \cdot$ R. Muilu-Mäkelä ${ }^{1} \cdot$ P. Kilpeläinen $^{2} \cdot$ E. Poikulainen ${ }^{3} \cdot$ T. Sarjala $^{1}$
}

Received: 2 November 2020 / Accepted: 15 February 2021

(c) The Author(s) 2021, corrected publication 2021

\begin{abstract}
Bryophytes, including Sphagnum, are common species in alpine and boreal regions especially on mires, where full sunlight exposes the plants to the damaging effects of UV radiation. Sphagnum species containing UV-protecting compounds might offer a biomass source for nature-based sunscreens to replace the synthetic ones. In this study, potential compounds and those linked in cell wall structures were obtained by using methanol and alkali extractions and the UV absorption of these extracts from three common Sphagnum moss species Sphagnum magellanicum, Sphagnum fuscum and Sphagnum fallax collected in spring and autumn from western Finland are described. Absorption spectrum screening (200-900 nm) and luminescent biosensor (Escherichia coli DPD2794) methodology were used to examine and compare the protection against UV radiation. Additionally, the antioxidant potential was evaluated using hydrogen peroxide scavenging (SCAV), oxygen radical absorbance capacity (ORAC) and ferric reducing absorbance capacity (FRAP). Total phenolic content was also determined using the Folin-Ciocalteu method. The results showed that methanol extractable compounds gave higher UV absorption with the used methods. Sphagnum fallax appeared to give the highest absorption in UV-B and UV-A wavelengths. In all assays except the SCAV test, the methanol extracts of Sphagnum samples collected in autumn indicated the highest antioxidant capacity and polyphenol content. Sphagnum fuscum implied the highest antioxidant capacity and phenolic content. There was low antioxidant and UV absorption provided by the alkali extracts of these three species.
\end{abstract}

Keywords Sphagnum moss · Ultraviolet absorbance $\cdot$ Methanol and alkali extracts · Antioxidant potential $\cdot$ GC-MS

\section{Introduction}

Chemical sunscreens are usually synthetic aromatic compounds conjugated with a carbonyl group. They protect from the damaging effect of UV radiation by absorbing rays of UV light and releasing the wavelengths of lower energy. However, UV absorption may activate the sunscreens, and they may consequently interact with cutaneous molecules, causing adverse skin reactions, such as dermatitis

J. Tienaho

jenni.tienaho@luke.fi

1 Production Systems Unit, Biomass Characterization and Properties Group, Natural Resources Institute Finland (Luke), Kaironiementie 15, 39700 Parkano, Finland

2 Production Systems Unit, Biorefinery and Bioproducts Group, Natural Resources Institute Finland (Luke), Tietotie 2, 02150 Espoo, Finland

3 Faculty of Natural Sciences and Engineering, Tampere University, Korkeakoulunkatu 8, 33101 Tampere, Finland or photosensitivity reactions [1]. Chemical sunscreens have also been shown to possess adverse environmental impacts. For example, oxybenzone was found to be genotoxic towards coral planulae and is therefore banned in Hawaii [2]. Sunscreen components were also demonstrated to induce coral bleaching by promoting viral infections to hard corals and their symbiotic algae [3]. These factors indicate an urgent need for broad-spectrum anti-UV radiation compounds derived from natural sources for the use of dermatology, cosmetics, and the coating industry.

Potential biomass to be studied for this use is the bryophytes, which are the dominant plant species in many UVrich areas, such as the alpine and polar regions, and on treeless and sparsely wooded mires. Niemi et al. [4] showed that increased UV radiation decreased the capitulum dry mass and induced a 30-40\% increase in the chlorophyll and carotenoid pigments of the Sphagnum sp. chosen for the study even with short sampling periods. This could be an indication of Sphagnum's rapid ability to adjust to adverse conditions. To promote this idea, a study by Clarke et al. 
[5] showed that another bryophyte, Ceratodon purpureus possessed high tolerance to UV, while it only contained low concentrations of the methanol-soluble UV-screening compounds. Therefore, they suggested that the found UV-filtering photoprotective potential is mainly originated from the cell-wall-bound compounds extracted via alkali-extraction.

In this study, samples of three common Sphagnum moss species adapted to different growth habitats with varying UV radiation, S. magellanicum, S. fuscum, and S. fallax, were collected in spring and autumn to consider seasonal variation. Three specimens of each species from both sample collections were then extracted using methanol and alkali extraction. To our knowledge, there are no studies available addressing the UV-filtering potential comparing the methanol-soluble and the alkali-soluble cell-wall-bound compounds of the chosen Sphagnum mosses. To detect the UV absorption ability, we used traditional absorbance screening (200-900 nm) and the physical luminescent microbial biosensor methodology described by Tienaho et al. [6]. This method embodies rapid high-throughput screening potential, cost-effectiveness and extreme sensitivity. Because the exposure to UV radiation causes a formation of reactive oxygen species (ROS) in plant and animal cells and tissues, it is well justified to link the UV-filtering potential to the antioxidant activity and polyphenol contents of the methanol and alkali extracts. This was achieved using hydrogen peroxide scavenging (SCAV, also ferrous oxidation in xylenol orange FOX) [7, 8], oxygen radical absorbance capacity $(\mathrm{ORAC})[9,10]$ and ferric reducing antioxidant power (FRAP) [11] antioxidant microplate tests. Folin-Ciocalteu reagent method [12] was used for determining total phenolic content. In addition, gas chromatography-mass spectrometry (GC-MS) was used for the characterization of compounds present within the extracts.

\section{Experimental}

\subsection{Chemicals}

Methanol (Lichlorosolv), chloroform, acetone, $\mathrm{NaOH}$, $\mathrm{Na}_{2} \mathrm{CO}_{3}, \mathrm{NaCOOH}$ and Folin-Ciocalteu reagent were purchased from Merck KGaA. $\mathrm{NaCl}$ was from J. T. Baker and sodium dodecyl sulphate (SDS, 20\%) from EuroClone. Gallic acid was from Sigma and formic acid (99\%) from VWR international. Ethanol (99.5\%) was from Altia, Finland.

\subsection{Sphagnum collections}

Three replicate samples of the surface layer of Sphagnum magellanicum, Sphagnum fallax and Sphagnum fuscum were collected from pristine mire in western Finland (Kaljakankaansuo, N61 ${ }^{\circ} 56.18^{\prime}$ E23 $3^{\circ} 19.87^{\prime}$ ). The long term
(1980-2010) annual mean temperature of the site was ca. $3.8^{\circ} \mathrm{C}$, the annual mean precipitation ca. $620 \mathrm{~mm}$ and the accumulative temperature sum $\left(>+5^{\circ} \mathrm{C}\right) \mathrm{ca} .1150$ degreedays. The mire site type of the study site was low sedge $S$. papillosum fen with large Sphagnum hummocks [13]. The surface of the study sites consisted of a typical pattern of boreal mires: from wet lawns to relatively dry hummocks. From a nutritional point of view, surfaces varied from poor minerotrophy (lawns) to ombrotrophy (hummocks). Dominant Sphagnum moss species on the hummocks were $S$. fuscum and S. magellanicum, and on the lawns S. magellanicum and $S$. fallax. The sampling was repeated twice, on the 28th of May 2018 and on the 24th of September 2018. The summer 2018 was very sunny and dry and Sphagnum mosses were extremely dry before the autumn rains. Visually normal and species-specific samples of the Sphagnum biomass were selected for this study. The fresh Sphagnum biomass was frozen and stored at $-20{ }^{\circ} \mathrm{C}$ for no more than $24 \mathrm{~h}$ prior to extraction.

\subsection{Extraction}

The samples were extracted first with methanol followed by consecutive alkali extraction, which was slightly modified from the study by Clarke et al. [5].

\subsubsection{Methanol extraction}

Two grams of the fresh Sphagnum capitula of each species (approximately $3 \mathrm{~cm}$ ) with three replicate samples were ground in a mortar. After adding $10 \mathrm{~mL}$ of methanol, the mixture was incubated at darkness and room temperature for one $\mathrm{h}$ in preweighed $15 \mathrm{~mL}$ polypropylene tubes (BD Falcon $^{\mathrm{TM}}$, VWR International Oy, Finland). The mixture was then centrifuged at 12,000 rpm for $10 \mathrm{~min}$ (10,350 Sigma 2-16KL Benchtop centrifuge), the supernatant was removed to a preweighed $15 \mathrm{~mL}$ polypropylene tube and dried using a vacuum centrifuge with a cooling unit (Rotational-VacuumConcentrator RVC 2-18, Cold Trap CT 02-50 SR, Martin Christ Gefriertrocknungsanlagen $\mathrm{GmbH}$, Osterode, Germany). The extraction yields (dry weight) in spring were 6.4-9.1 mg (0.32-0.46\%) for S. magellanicum, $11.6-18.7 \mathrm{mg}$ (0.58-0.94\%) for S. fallax, and 6.1-7.3 mg (0.31-0.37\%) for S. fuscum. In autumn the extraction yields (dry weight) were $5.7-7.9 \mathrm{mg}(0.29-0.40 \%)$ of $S$. magellanicum, $10.7-11.9 \mathrm{mg}$ (0.53-0.60\%) of S. fallax, and 5.3-6.7 mg (0.27-0.34\%) of S. fuscum. Prior to the tests, the dry extracts were dissolved in water adjusting equal concentrations for all the samples.

\subsubsection{Alkali extraction}

The remaining cell debris or pellet was incubated in $1 \mathrm{M}$ $\mathrm{NaCl}$, twice in $0.5 \%$ (w/v) SDS and again twice using 
chloroform/methanol $(1: 1, \mathrm{v} / \mathrm{v})$, each for $20 \mathrm{~min}$ and centrifuged at 12,000 rpm for $5 \mathrm{~min}$ in between. The pellet was then washed with acetone before drying in a vacuum centrifuge. After drying, the pellet was incubated for $16 \mathrm{~h}$ in darkness with $1 \mathrm{M} \mathrm{NaOH}$ and then centrifuged for $15 \mathrm{~min}$ in 12,000 rpm. The volume of the supernatant was then measured and moved into a new $50 \mathrm{~mL}$ polypropylene tube. The extraction product was neutralized using an equal amount $(\mathrm{v} / \mathrm{v})$ of $1.5 \mathrm{M}$ formic acid and centrifuged again for $5 \mathrm{~min}$ in $12,000 \mathrm{rpm}$. The final extraction product was then pipetted into preweighed polypropylene tubes and dried using a vacuum centrifuge. Both extracts were stored at $-20{ }^{\circ} \mathrm{C}$ until analyzed. The extraction yields (dry weight) in spring were $644.0-687.6 \mathrm{mg}(32.2-34.4 \%)$ for $S$. magellanicum, 575.5-636.8 mg (28.8-31.8\%) for S. fallax, and 542.4-552.9 mg (27.1-27.6\%) for S. fuscum. In autumn the extraction yields (dry weight) were $528.6-547.5 \mathrm{mg}$ (26.4-27.4\%) of S. magellanicum, $587.5-667.0 \mathrm{mg}$ (29.4-33.4\%) of S. fallax, and 482.2-536.2 mg (24.1-26.8\%) of $S$. fuscum. The dry weights of alkali extracts were higher because these included the cell wall debris of the Sphagnum biomass. Prior to the tests, the dry extracts were dissolved in water adjusting equal concentrations for all the samples.

\subsection{UV Absorbance}

\subsubsection{Biosensor analysis}

The DNA damage-induced stress-responsive biosensor strain E. coli DPD2794 originally described by Vollmer et al. [14] was used with physical screening methodology described in Tienaho et al. [6]. Because the luminescent light production can vary depending on the chosen culture, the results are expressed as induction factors $\left(\mathrm{IF}=\right.$ Average $_{\text {sample triplicates }}$ ' Average $_{\text {negative control triplicates). Higher luminescent light sig- }}$ nals are given for samples with low protection from UV irradiation. In the physical test methodology, the samples are not in contact with the bacterial cells. Instead, the samples are placed directly over the cell cultures, which allows UV irradiation protection but minimizes the possibility of the sample itself inducing stress reaction in the bacterial cells. Because the material was limited and the test gives evidence of the sample's ability of protecting bacteria only from the UV-C irradiation ( $254 \mathrm{~nm}$ ), biosensor analysis was conducted solely for the spring collection. Both methanol and alkali extracts were dissolved in double distilled water to achieve the concentrations of $1.66 ; 0.83$ and $0.42 \mathrm{mg} / \mathrm{mL}$ per microplate well.

\subsubsection{Spectrophotometric analysis}

Absorbance screening was executed for all samples. The absorbance of $100 \mu \mathrm{L}$ of the extract with three replicates in a translucent microplate (Sarstedt AG \& Co, Germany) was measured using Thermo Scientific Varioskan Flash Reader (Thermo Fischer Scientific, Thermo Electron Co. USA) in the absorbance scan mode with $5 \mathrm{~nm}$ intervals for the wavelength area of $200-900 \mathrm{~nm}$ as described by Tienaho et al. [2]. Averages and standard deviations were calculated for the sample replicates.

\subsection{Antioxidant and total phenolic content tests}

\subsubsection{SCAV}

This test measures the hydrogen peroxide scavenging ability of the samples. In order to be active in this test the substance needs to inhibit the Fenton reaction, where hydrogen peroxide oxidizes $\mathrm{Fe}(\mathrm{II})$ into $\mathrm{Fe}(\mathrm{III})$, which yields hydroxyl radicals. The used methodology was modified from the methods described by Hazra et al. [7] and Jiang et al. [8]. In brief, four technical replicates of $30 \mu \mathrm{L}$ were measured in 96-well format as in Välimaa et al. [15] or Tienaho et al. [16]. An aliquot of $2 \mathrm{mM} \mathrm{H}_{2} \mathrm{O}_{2}$ (Merck KGaA, Darmstadt Germany) was added to the reaction mixture with the sample, $111 \mu \mathrm{M}$ xylenol orange disodium salt (Sigma Aldrich Chemie GmbH, Steinheim, Germany) and $2.56 \mathrm{mM}$ ammonium iron (II) sulphate $6 \mathrm{H}_{2} \mathrm{O}$ (BDH Prolabo). The absorbance was measured at $560 \mathrm{~nm}$ after $30 \mathrm{~min}$ incubation. The scavenging ability is expressed as the inhibition percentage (\%) of Fe(II) oxidation to Fe(III). Sodium pyruvate (SigmaAldrich Chemie GmbH, Steinheim, Germany) was used as a positive control.

\subsubsection{ORAC}

This test was used to measure the ability of a potential antioxidant to prevent peroxyl radicals from harming the fluorescent fluorescein molecule. The used methodology is modified from the methods described by Huang et al. [9] and Prior et al. [10]. In brief, two technical replicates of $50 \mu \mathrm{L}$ were measured in 96-well format as in Välimaa et al. [15] or in Tienaho et al. [16]. All samples were measured with a series of five dilutions (1:1-1:320) and additional dilutions were added when necessary to adjust the sample concentrations to the $0.153 \mathrm{mM}$ Trolox $(( \pm)-6$-Hydroxy-2,5,7,8-tetramethylchromane-2-carboxylic acid) (Sigma-Aldrich Chemie $\mathrm{GmbH}$, Steinheim, Germany) standard curve. The reaction mixture contained the sample dilution, in $75 \mathrm{mM}$ phosphate buffer $\mathrm{pH} 7.5$ (Merck), $150 \mu \mathrm{L}$ of $8.16 \times 10^{-5} \mathrm{mM}$ fluorescein (Sigma-Aldrich Chemie GmbH, Steinheim, Germany) and $25 \mu \mathrm{L}$ of 2,2'-Azobis(2-methylpropionamidine) dihydrochloride (Sigma-Aldrich Chemie GmbH, Steinheim, Germany). The results are expressed as Trolox equivalents ( $\mu \mathrm{mol} \mathrm{TE} / \mathrm{g}$ ). 


\subsubsection{FRAP}

This test measures the reducing capacity of a potential antioxidant. To be active in this test the substance must be able to reduce $\mathrm{Fe}(\mathrm{III})$ into $\mathrm{Fe}(\mathrm{II})$. The used methodology is modified from the method described by Benzie and Strain [11]. Three technical replicates of $25 \mu \mathrm{L}$ were measured in 96-well format as in Välimaa et al. [15]. The reaction mixture contained the sample, $20 \mathrm{mM} \mathrm{FeCl}{ }_{3} \cdot 6 \mathrm{H}_{2} \mathrm{O}$ (Sigma-Aldrich Chemie GmbH, Steinheim, Germany) and $10 \mathrm{mM}$ 2,4,6-Tris(2-pyridyl)-s-triazine (TPTZ) (SigmaAldrich Chemie GmbH, Steinheim, Germany) in $300 \mathrm{mM}$ acetate buffer $\mathrm{pH}$ 3.6. The formation of ferrous-tripyridyltriazine complex in the reaction mixture is measured by absorbance at $593 \mathrm{~nm}$ and series of dilutions to fit the sample to the standard curve. $\mathrm{FeSO}_{4} \cdot 7 \mathrm{H}_{2} \mathrm{O}$ (SigmaAldrich Chemie $\mathrm{GmbH}$, Steinheim, Germany) was used as a standard compound and $\mathrm{L}(+)$-ascorbic acid $(150 \mu \mathrm{M}$ and $800 \mu \mathrm{M})$ (VWR Chemicals) as a control and the results are expressed as $\mu \mathrm{mol} / \mathrm{L} \mathrm{Fe}(\mathrm{II})$ equivalents.

\subsubsection{Folin-Ciocalteu}

This test measures the total phenolic content of the samples. Phenolic compounds and polyphenols have been found to possess antioxidant capacity. They scavenge oxygen radicals and break the radical chain sequences as well as interrupt the lipid peroxidation process. In the method, molybdotungstophosphoric heteropolyanion oxidizes phenolic compounds in alkalic solution forming a blue molybdotungstophosphate complex [12]. The absorbance was measured at $750 \mathrm{~nm}$ and the results were compared against gallic acid (29.4 mM, Sigma-Aldrich Chemie GmbH, Steinheim, Germany) standard curve. The reaction mixture contained the sample, Folin-Ciocalteu reagent (Merck), and 20\% $\mathrm{Na}_{2} \mathrm{CO}_{3}$ (Merck). The results are expressed as Gallic acid equivalents (mg GAE/g).

\subsection{Statistical methods}

The effect of Sphagnum species, sampling date (May and September), and their interactions on total phenol contents, and on the antioxidant action levels (SCAV, ORAC and FRAP test results) were analysed by the linear regression model. The sampling date and species were included as categorical factors with fixed effects, such that their reference levels were sampling date I (May) and Species (S. magellanicum). The models were fitted using the function $\operatorname{lm}$ [17] of the $\mathrm{R}$ environment version 3.6.1 [18]. The analysis was performed separately for methanol and alkali extractions.

\subsection{Chemical analysis}

Chemical analysis of methanol and alkali extracts was performed by using a HP 6890 GC system equipped with a mass selective detector HP 5973 and ZB-SemiVolatiles capillary column ( $30 \mathrm{~m} \times 0.25 \mathrm{~mm}$ i.d.; $0.25 \mu \mathrm{m}$ film thickness). Helium was used as a carrier gas, at a flow rate of $1.5 \mathrm{~mL} /$ min. Heneicosanoic acid (C:21) and Betulin were used as internal standards. The chromatographic conditions were as follows: initial temperature $150{ }^{\circ} \mathrm{C}$; temperature rate $7{ }^{\circ} \mathrm{C} /$ min to $230{ }^{\circ} \mathrm{C}$ and $4{ }^{\circ} \mathrm{C} / \mathrm{min}$ final temperature $310{ }^{\circ} \mathrm{C}$ for $20 \mathrm{~min}$; injector temperature $280^{\circ} \mathrm{C}$ and split ratio $1: 20$, MS-interface temperature was $300^{\circ} \mathrm{C}$, and ion source temperature $230{ }^{\circ} \mathrm{C}$. Mass spectra were obtained by electron impact (EI mode) ionization energy $70 \mathrm{eV}$. The samples were silylated prior to the analysis with $0.5 \mathrm{~mL} 20 \%$ TMSIpyridine mixture $(\mathrm{TMSI}=1$-(trimethylsilyl) imidazole).

\section{Results and discussion}

\subsection{UV absorption}

UV absorption capacity was measured with two methodologies for the samples collected in spring and only using absorbance screening for the autumn collection. The results using physical biosensor methodology are shown in Fig. 1. Because the used DNA damage-induced stress-responsive sensor emits luminescence as a reaction to the stress, the higher the IF signal, the less the sample has been able to protect the bacteria. Luria broth growth medium was used as the positive control in the method and only S. fuscum (at the content of 1.67 and $0.84 \mathrm{mg} / \mathrm{ml}$ ) and $S$. magellanicum (at the content of $1.67 \mathrm{mg} / \mathrm{ml}$ ) methanol extracts gave lower IF values indicating higher UV irradiation protection with the screening method (Fig. 1a). However, all the methanol extracts gave lower values than the negative control (water). In the case of alkali extracts, all gave higher IF values than the positive or negative control (Fig. 1b) indicating no UV irradiation protection. Interestingly, in this study, alkali extracts seem to increase the UV irradiation-induced damage in the used Escherichia coli biosensor even without a contact with the strain. The reason for this is unclear. It may be that the refraction index of neutralized $\mathrm{NaOH}$ or washing solvent residues in the extracts are smaller than the water control's, which would increase the amount of UV irradiation going through to the bacteria.

The results from traditional UV-Vis region screening are shown in Fig. 2. It seems that although $S$. fuscum methanol extract had the highest absorbance in the UV-C region (250-280 nm) S. fallax had higher absorbance through the whole UV-B region (280-315 nm) in autumn and for $280-290 \mathrm{~nm}$ in spring. The concentrations of the extracts 


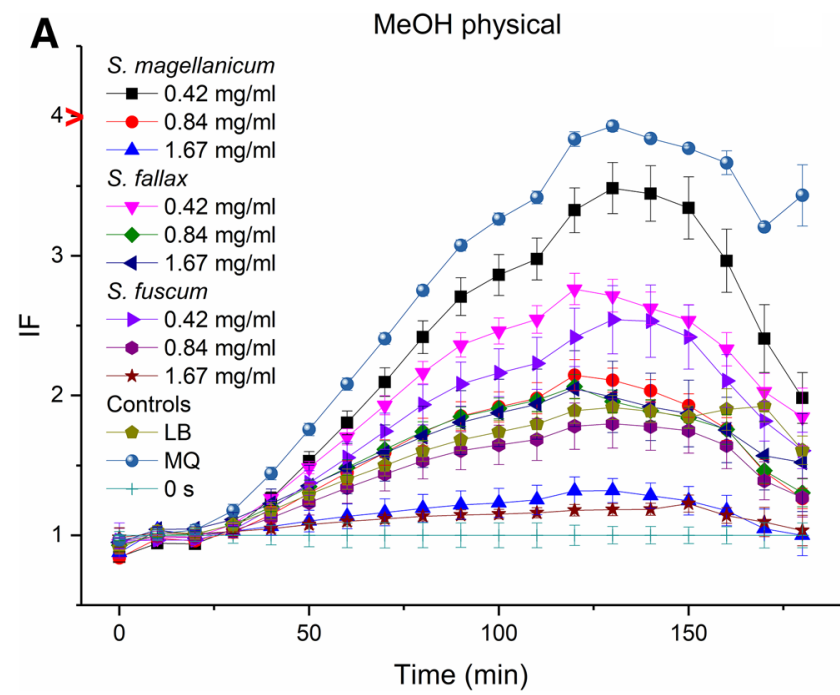

Fig. 1 The UV irradiation protection of $\mathrm{MeOH}$ extracts (a) and $\mathrm{NaOH}$ extracted fractions (b) of Sphagnum mosses collected in the spring (mean \pm standard deviation) measured with the bioscreening method at the UV irradiation wavelength $254 \mathrm{~nm}$ [6]. LB=lysogeny broth growth medium, which is used as a positive control. $\mathrm{MQ}=$ Double-distilled water, which is used as the negative control.

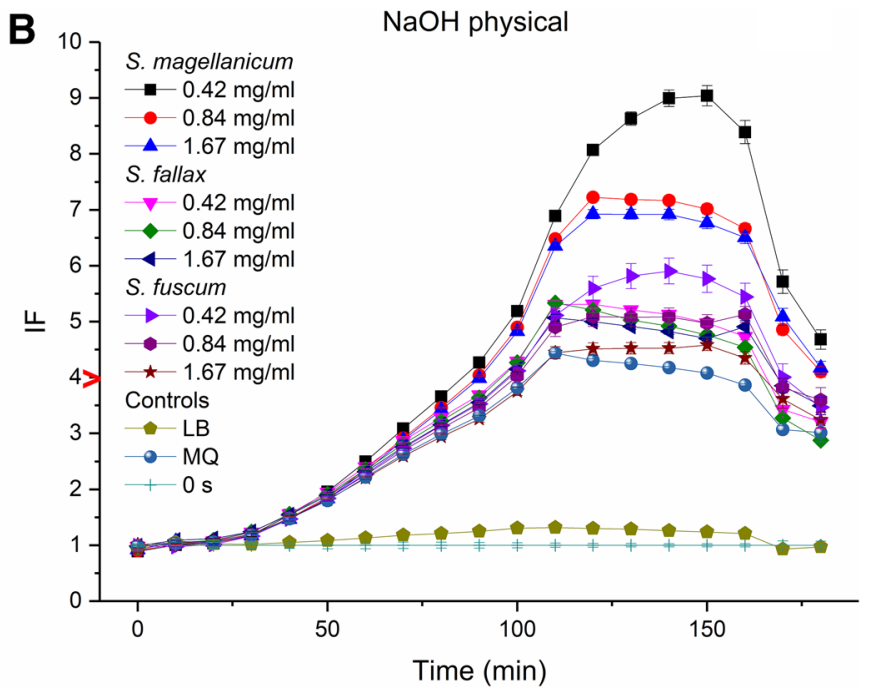

$0 \mathrm{~s}=$ shows the normal growth of the biosensor cells without UV exposure. IF =induction factor; ( $\mathrm{IF}=$ Average(sample triplicates)/ Average(negative control triplicates)). The higher the IF value of the sample at a given time point, the less the sample is protecting the bacteria from the UV irradiation
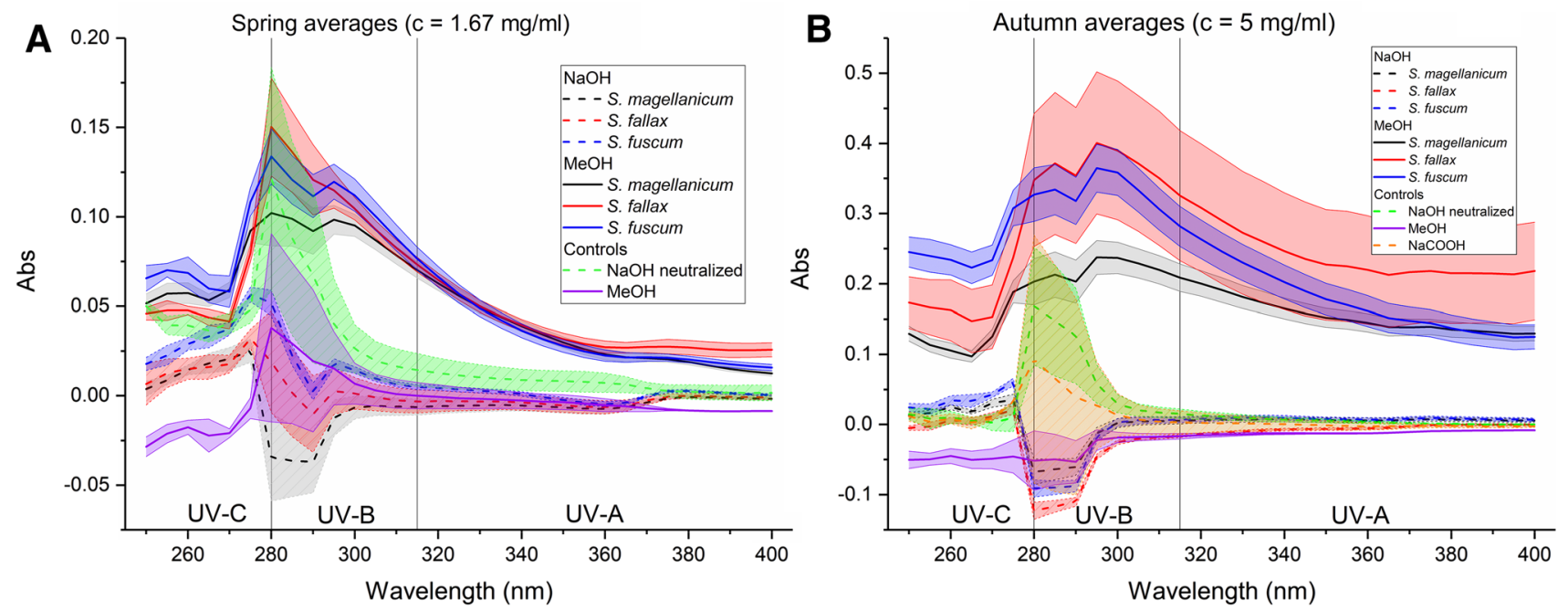

Fig. 2 UV light absorbance of $\mathrm{MeOH}$ and $\mathrm{NaOH}$ extracts of Sphagnum mosses in spring (a $c=1.67 \mathrm{mg} / \mathrm{ml})$ and autumn $(\mathbf{b} c=5.00 \mathrm{mg} / \mathrm{ml})$ (mean \pm standard deviation, $n=3$ )

differ between spring and autumn because of the altering collected Sphagnum biomass quantity. This difference does not impact the UV absorption profiles as can be seen from Fig. 2. S. fallax gives the strongest absorbance in the UV-A region as well $(315-400 \mathrm{~nm})$. This is particularly clear in the autumn (Fig. 2b) with slightly higher concentrations but is detectable in spring as well from 335-400 nm (Fig. 2a). Some absorbance can be detected in the UV-C region for the alkali extracts, but absorbance is negative in the UV-B region. This is unusual behavior for plant extracts. As the neutralized $\mathrm{NaOH}$ and the $\mathrm{NaCOOH}$ salt both have positive absorption in the UV-B region (Fig. 2), it could be due to some washing solvent residues in the alkali extracts causing a shift to the refraction index. Surprisingly, S. fallax, although adapted to the shadiest growing habitats, had the strongest UV absorbance properties. This may be due to the different growing optimum with respect to nutrition status and water table level when compared with the two other 
Sphagnum moss species, $S$. fuscum and $S$. magellanicum. It is also possible that $S$. fallax has stronger UV absorption to adapt to various UV radiation conditions, where dark shadows caused by the trees shift suddenly to open sunshine. This sudden increase in high light is called a sunfleck and it can cause large shifts in the quality of light received by plants in the understory.

\subsection{Antioxidant and phenols tests}

Antioxidant and phenols test results are summarized in Fig. 3 and Supplementary Table S1. All the three antioxidant activity tests and phenol contents indicated that there was no difference between Sphagnum species in methanol extracts in spring. Phenol contents increased in all species in September, being on the highest level in S. fuscum. The phenolic content showed correlation with the antioxidant test results indicating that methanol-extractable polyphenols may contribute to the antioxidant power. The increase in the phenolic content may also contribute to the increase in the absorbance in the UV-B region (Fig. 2).

The higher antioxidant power of the methanol extracts was measured in autumn than in spring. The SCAV values differed from the other test results. The antioxidant assays used here cover the distinct antioxidant mechanisms: hydrogen atom transfer (HAT) by ORAC, single electron transfer (SET) by FRAP and the ability to chelate transition metals by SCAV. Polyphenols have been shown to absorb the UV wavelengths and to scavenge UV generated ROS and, thus, alleviate the harming effects of UV radiation [1]. Plants protect themselves from the harming physiological effects of excess solar radiation by accumulating polyphenolic compounds, such as flavonoids [19]. Additionally, plants use pigmentation to protect chlorophylls and DNA and it is usually achieved via anthocyanins, which are a form of flavonoids [20]. Sphagnum mosses have been shown to possess higher amounts of phenolic compounds than other bryophytes in general although the level is still low when
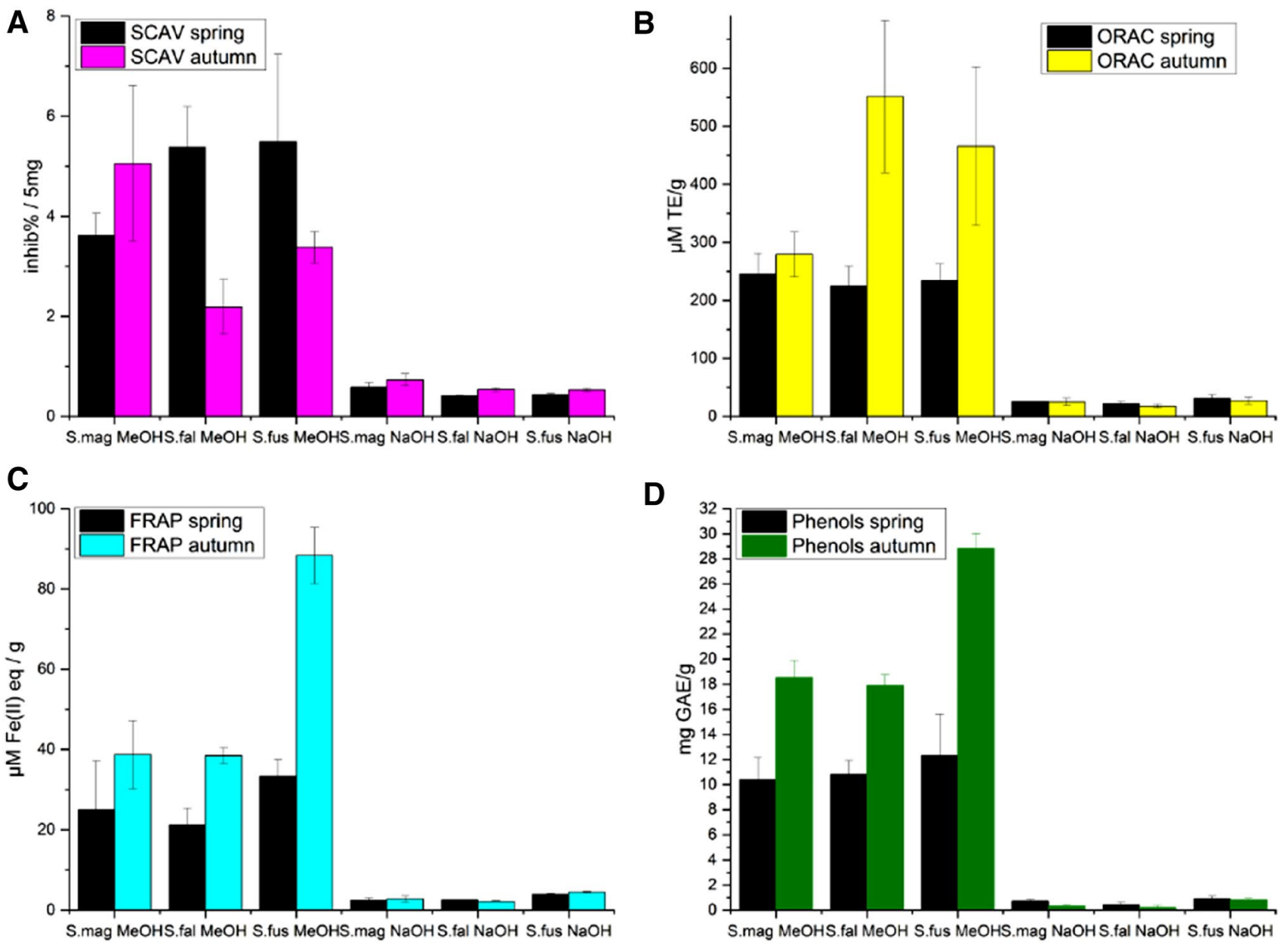

Fig. $3 \mathrm{H}_{2} \mathrm{O}_{2}$ scavenging (SCAV) (a), ORAC (b) and FRAP (c) values as well as total phenolic content (d) of the methanol and alkali extracts of the three Sphagnum moss species collected in spring and

autumn. The values present the averages \pm standard deviations $(n=3)$ per dried extract. S.mag, S. magellanicum; S.fal, S. fallax; S.fus, S. fuscum 
in comparison with other plants [21]. The comparison of different studies is challenging because of different units in the determination of the phenolic content. The highest concentration of free phenolics has been found in the capitula, which constitutes mostly living tissues with the active metabolic processes of Sphagnum [22, 23]. The amount of bound phenolics in S. fallax at $20{ }^{\circ} \mathrm{C}$ after 8 weeks was $3.4 \mathrm{mg} / \mathrm{g}$ (dry weight) and the amount of free phenolics $1.6 \mathrm{mg} / \mathrm{g}$ (dry weight) in the upper segment (0-3 cm from the capitulum) and $1.7 \mathrm{mg} / \mathrm{g}$ (dry weight) and $0.6 \mathrm{mg} / \mathrm{g}$ of dry weight in the lower segment (3-6 cm from the capitulum) of Sphagnum, respectively [22]. In this study, S. fuscum showed the highest phenolic content in the autumn and consequently the highest antioxidant power in the FRAP test. Sphagnum fallax autumn extract showed higher antioxidant activity in the ORAC test than the other two species $S$. fuscum and S. magellanicum. In the SCAV test, the highest antioxidant activity seems to account to the spring extracts whereas the SCAV activity decreased towards autumn in S. fallax and $S$. fuscum methanol extracts and remained stable in S. magellanicum. In alkali extraction, SCAV activity increased in S. magellanicum towards the autumn but remained stable in other species. In alkali extracts, FRAP activity was the highest in S. fuscum in spring. Phenolic content was probably more related to the FRAP activity due to its stronger correlation than that with ORAC. Both FRAP and ORAC activity and the phenolic content of alkali extracts showed 10-20 times lower values than those of methanol extracts. This indicates that the alkali extracted cell-wall associated compounds were not responsible for the UV absorption or the antioxidant power of the samples unlike with Ceratodon purpureus in an earlier study [5].

\subsection{Characterization using GC-MS}

Characterization results from the Sphagnum species can be found in Tables 1 ( $\mathrm{MeOH}$ extracts) and $2(\mathrm{NaOH}$ extracts) and gas chromatograms can be seen on Figs. 4, 5, respectively. The amount of internal standards are the same in both figures, which emphasizes the fact that alkali extracts have smaller amounts of other substances. Most identified compounds were different carbohydrates, which is in accordance with the earlier studies [21]. However, campesterol and $\beta$-sitosterol have conjugated carbons in their ring structures, and they have been reported with UV $\lambda_{\max }$ at $257 \mathrm{~nm}$ and $251 \mathrm{~nm}$ in petroleum ether extracts, respectively [24]. Sitorus et al. [25] reported that $\beta$-sitosterol in ethanol has a UV $\lambda_{\max }$ at $268.5 \mathrm{~nm}$. These compounds can therefore participate in the UV absorbance of the Sphagnum samples.
Table 1 GC-MS characterized compounds from the methanol extractions

\begin{tabular}{|c|c|c|c|c|c|c|c|}
\hline \multicolumn{2}{|c|}{$\mathrm{MeOH}$} & \multicolumn{2}{|c|}{ S. fallax } & \multicolumn{2}{|c|}{ S. magellanicum } & \multicolumn{2}{|c|}{ S. fuscum } \\
\hline \# & Compound & RT & A\% & RT & $\mathrm{A} \%$ & RT & $\mathrm{A} \%$ \\
\hline 1 & Fructose & 6.06 & 25.6 & 6.04 & 10.3 & 6.04 & 21.6 \\
\hline 2 & Mannose & 7.01 & 15.9 & 7.01 & 8.1 & 7.01 & 20.3 \\
\hline 3 & Glucose & 7.14 & 0.6 & 7.15 & 0.6 & 7.14 & 1.3 \\
\hline 4 & Sorbitol & 7.46 & 0.5 & 7.46 & 1.7 & 7.46 & 2.9 \\
\hline 5 & Glucose & 8.15 & 14.8 & 8.15 & 7.5 & 8.15 & 20.2 \\
\hline 6 & Palmitic acid & 9.06 & 1.7 & 9.07 & 1.0 & 9.06 & 1.1 \\
\hline 7 & Myo-inositol & 9.53 & 1.3 & 9.53 & 1.1 & 9.53 & 2.7 \\
\hline 8 & Galactose & 11.38 & 8.8 & 11.38 & 5.9 & 11.38 & 6.9 \\
\hline 9 & Glucuronic acid & 13.29 & 0.1 & 13.30 & 0.4 & 13.29 & 0.3 \\
\hline 10 & ISTD1 & 15.70 & 11.1 & 15.70 & 10.8 & 15.70 & 13.4 \\
\hline 11 & Monopalmitin & 16.41 & 1.5 & 16.41 & 1.4 & 16.41 & 1.4 \\
\hline 12 & Saccharose & 17.08 & 100 & 17.08 & 100 & 17.07 & 100 \\
\hline 13 & Raffinose & 18.36 & 0.5 & 18.36 & 0.8 & 18.36 & 1.3 \\
\hline 14 & Trisaccharose & 18.67 & 0.4 & 18.67 & 2.7 & 18.66 & 3.8 \\
\hline 15 & Monostearin & 19.41 & 8.6 & 19.41 & 9.1 & 19.41 & 9.3 \\
\hline 16 & Campesterol & 26.30 & 0.5 & 26.30 & 0.2 & 26.69 & 0.4 \\
\hline 17 & $\beta$-sitosterol & 27.60 & 0.6 & 27.60 & 0.4 & 27.59 & 0.2 \\
\hline 18 & Stachyose & 28.73 & 11.2 & 28.73 & 11.8 & 28.72 & 10.2 \\
\hline 19 & ISTD2 & 30.74 & 17.0 & 30.74 & 16.9 & 30.74 & 20.8 \\
\hline
\end{tabular}

RT, retention time; A\%, relative peak area compared to the highest peak. Internal standards: ISTD1 $=$ Heneicosanoic acid; ISTD2=Betulin. The gas chromatogram of $S$. fallax is shown in Fig. 4 and other chromatograms as well as the corresponding mass spectra can be found from the Supplementary material 
Table 2 GC-MS characterized compounds from the alkali extractions

\begin{tabular}{|c|c|c|c|c|c|c|c|}
\hline \multicolumn{2}{|c|}{$\mathrm{NaOH}$} & \multicolumn{2}{|c|}{ S. fallax } & \multicolumn{2}{|c|}{ S. magellanicum } & \multicolumn{2}{|c|}{ S. fuscum } \\
\hline \# & Compound & RT & $\mathrm{A} \%$ & RT & $\mathrm{A} \%$ & RT & $\mathrm{A} \%$ \\
\hline 1 & Arabinose & 3.81 & 56.5 & 3.81 & 48.1 & 3.81 & 46.9 \\
\hline 2 & Arabinose & 4.13 & 37.4 & 4.12 & 55.2 & 4.12 & 76.0 \\
\hline 3 & Fructose & 5.99 & 17.9 & 5.81 & 22.9 & 5.93 & 42.3 \\
\hline 4 & Mannose & 7.01 & 15.5 & 7.01 & 18.9 & 7.01 & 18.1 \\
\hline 5 & Glucose & 7.13 & 17.2 & 7.13 & 22.4 & 7.13 & 35.1 \\
\hline 6 & Glucose & 8.15 & 20.8 & 8.15 & 17.1 & 8.15 & 19.7 \\
\hline 7 & Palmitic acid & 9.06 & 100 & 9.06 & 100 & 9.06 & 100 \\
\hline 8 & Stearic acid & 11.58 & 56.0 & 11.58 & 58.2 & 11.58 & 56.3 \\
\hline 9 & ISTD1 & 15.70 & 1525 & 15.70 & 1723 & 15.70 & 1791 \\
\hline 10 & Saccharose & 17.07 & 7.2 & 17.06 & 6.6 & 17.06 & 10.4 \\
\hline 11 & ISTD2 & 30.75 & 2656 & 30.75 & 2989 & 30.75 & 3296 \\
\hline
\end{tabular}

The gas chromatogram of $S$. fallax is shown in Fig. 5 and other chromatograms, as well as the corresponding mass spectra, can be found from the Supplementary material

RT, retention time; A\%, relative peak area compared to the highest peak; ISTD1, Heneicosanoic acid; ISTD2, Betulin

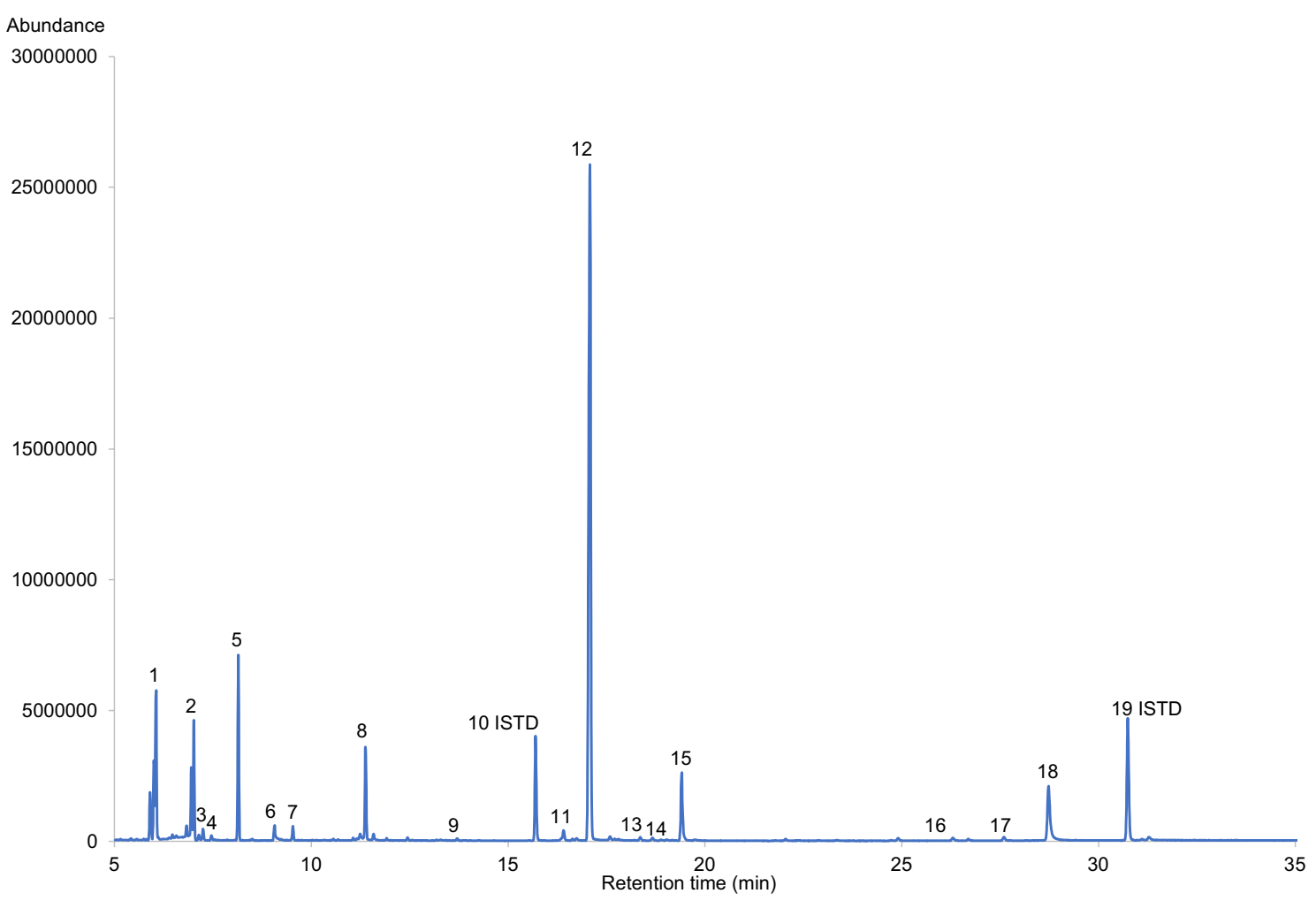

Fig. 4 The gas chromatogram of $S$. fallax methanol extract. All the chromatograms can be found from the supplementary material and they were similar for all species

Additionally, some unidentified compounds were observed (see Figs. 4 and 5 and Supplementary material). However, despite being low for all bryophytes, the phenolic composition has been reported and Sphagnum moss contains catechols, phenolcarboxylic acids and flavonols
[26]. Additionally, lignin-like phenolics have been reported from Sphagnum, while structural analysis has not been able to verify their existence in moss [21]. Sphagnum acid ( $p$-hydroxy- $\beta$-carboxymethyl-cinnamic acid) is considered the most abundant phenolic compound in Sphagnum and it 


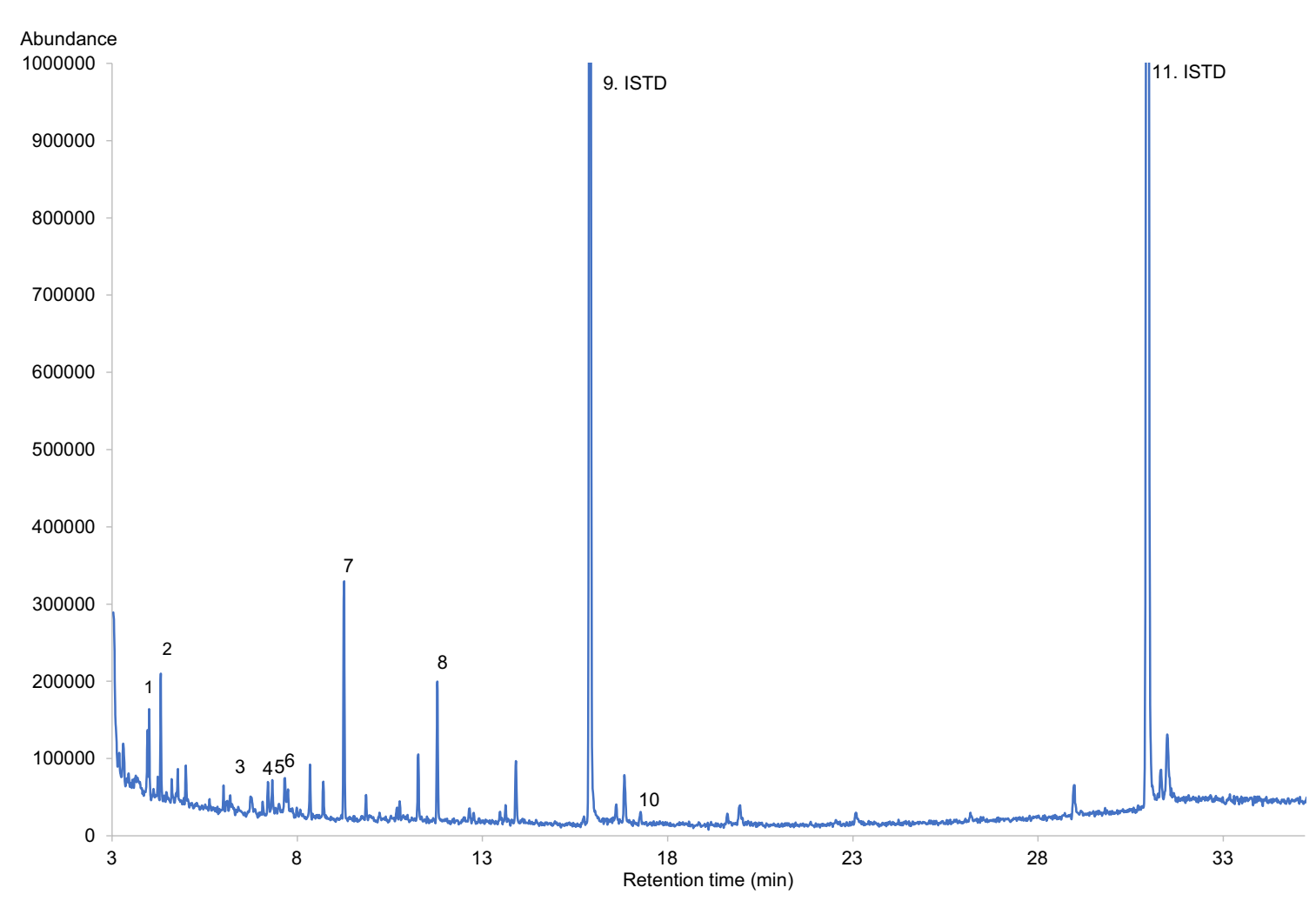

Fig. 5 The gas chromatogram of S. fallax alkali extract. All the chromatograms can be found from the supplementary material and they were similar for all species

is a decomposition product of lignin-like phenolics [21]. The metabolic profile of Sphagnum fallax has been described by Fudyma et al. [27] and a total of 655 metabolites out of which 329 were completely novel were identified using liquid chromatography-mass spectrometry LC-MS from lyophilized and Folch extracted biomass. The approach used in this study was qualitative analysis whereas more detailed analyses could be executed in further studies using LC-MS techniques.

\section{Conclusions}

In this study, UV absorption capacity and antioxidant power of Sphagnum magellanicum, Sphagnum fuscum and Sphagnum fallax both in spring and autumn were evaluated using methanol and alkali extraction. We found that methanol extractable compounds showed higher UV absorbance and antioxidant power whereas alkali extractable compounds gave significantly lower values in all tests. This must result from the extracts containing less UV absorbent, phenolic and ROS scavenging components than the methanol extracts. Interesting opportunities for future research arise from a possibility to acidify the alkali extracts down to $\mathrm{pH} 1$ as has been previously examined for pine, liverworths and moss samples [28-30]. Acidification shows the importance for the extraction of compounds containing hydroxyl groups, which are often responsible for the antioxidant properties. By acidifying the alkali extracts, the antioxidant and UV absorption properties of the fraction could therefore improve. While $S$. fuscum methanol extract gave the highest absorption in the UV-C region, $S$. fallax indicated the highest absorption capacity in both UV-B and UV-A regions. UV-absorption was quite similar in spring and autumn. The highest phenolic content and the highest antioxidant power in the FRAP test were found in $S$. fuscum in autumn. The highest ORAC activity was shown in S. fallax and S. fuscum in autumn. In the SCAV test, the highest antioxidant activity accounts to the spring extracts and difference between S. fallax and S. fuscum is not significant. Only S. magellanicum gave higher activity in autumn. The metabolic profile of plants naturally varies during the year and metabolic changes related to the end of the growing season may affect the differences found in the activities between seasons. The GC-MS characterization verified the earlier finding that the majority of Sphagnum extractables are carbohydrates. However, the phytosterols characterized from the methanol extracts could participate in the UV absorbance of the samples. Earlier research has shown that bryophytes, in general, have low amounts of phenolic compounds and most of these 
are catechols, phenolcarboxylic acids, flavonols, lignin-like phenolics or their decomposition products [21, 26]. LC-MS could identify further potentially active components and therefore be considered as an appropriate analysis equipment for future studies. This study indicates that the methanol extractable rather than the $\mathrm{NaOH}$ extractable cell-wall associated compounds are contributing to the UV absorption properties in the investigated Sphagnum species.

Supplementary Information The online version contains supplementary material available at https://doi.org/10.1007/s43630-021-00026-w.

Funding Open access funding provided by Natural Resources Institute Finland (LUKE). This study was funded by Natural Resources Institute Finland as a budget-funded project of Boreal Green Bioeconomy strategic funds for year 2018. J. Tienaho also received a personal grant from Kone Foundation.

Availability of data and material The datasets generated and analysed during the current study are available from the corresponding author on reasonable request.

Electronic Supplementary Information (ESI) available: Baseline relative phenol content and antioxidant properties and estimated relative contrasts can be found in Supplementary file 1. Supplementary material also contains the gas chromatograms for all Sphagnum species (Supplementary file 2) and the mass spectra for the identified compounds (Supplementary file 3). See DOI: https://doi.org/10.1039/x0xx00000x.

\section{Compliance with ethical standards}

Conflicts of interest The authors have no relevant financial or nonfinancial interests to disclose.

Open Access This article is licensed under a Creative Commons Attribution 4.0 International License, which permits use, sharing, adaptation, distribution and reproduction in any medium or format, as long as you give appropriate credit to the original author(s) and the source, provide a link to the Creative Commons licence, and indicate if changes were made. The images or other third party material in this article are included in the article's Creative Commons licence, unless indicated otherwise in a credit line to the material. If material is not included in the article's Creative Commons licence and your intended use is not permitted by statutory regulation or exceeds the permitted use, you will need to obtain permission directly from the copyright holder. To view a copy of this licence, visit http://creativecommons.org/licenses/by/4.0/.

\section{References}

1. Stevanato, R., Bertelle, M., \& Fabris, S. (2014). Photoprotective characteristics of natural antioxidant polyphenols. Regulatory Toxicology and Pharmacology. https://doi.org/10.1016/j.yrtph. 2014.02.014

2. Downs, C., Kramarsky-Winter, E., Segal, R., Fauth, J., Knutson, S., Bronstein, O., et al. (2016). Toxicopathological effects of the sunscreen UV Filter, Oxybenzone (Benzophenone-3), on Coral Planulae and cultured primary cells and its environmental contamination in Hawaii and the US Virgin Islands. Archives of Environmental Contamination and Toxicology. https://doi.org/10. 1007/s00244-015-0227-7
3. Danovaro, R., Bongiorni, L., Corinaldesi, C., Giovannelli, D., Damiani, E., Astolfi, P., et al. (2008). Sunscreens cause coral bleaching by promoting viral infections. Environmental Health Perspectives. https://doi.org/10.1289/ehp.10966

4. Niemi, R., Martikainen, P., Silvola, J., Sonninen, E., Wulff, A., \& Holopainen, T. (2002). Responses of two Sphagnum moss species and Eriophorum vaginatum to enhanced UV-B in a summer of low UV intensity. New Phytologist. https://doi.org/10.1046/j. 1469-8137.2002.00532.x

5. Clarke, L., \& Robinson, S. (2008). Cell wall-bound ultravioletscreening compounds explain the high ultraviolet tolerance of the Antarctic moss. Ceratodon purpureus: New Phytologist. https:// doi.org/10.1111/j.1469-8137.2008.02499.x

6. Tienaho, J., Poikulainen, E., Sarjala, T., Muilu-Mäkelä, R., Santala, V., \& Karp, M. (2018). Photochemistry \& Photobiology. https://doi.org/10.1111/php.12954

7. Hazra, B., Biswas, S., \& Mandal, N. (2008). Antioxidant and free radical scavenging activity of Spondias pinnata. BMC Complementary and Alternative Medicine. https://doi.org/10.1186/ 1472-6882-8-63

8. Jiang, Z.-Y., Woollard, A., \& Wolff, S. (1990). Hydrogen peroxide production during experimental protein glycation. FEBS Letters. https://doi.org/10.1016/0014-5793(90)80974-n

9. Huang, D., Ou, B., Hampsch-Woodill, M., Flanagan, J., \& Prior, R. (2002). High-throughput assay of oxygen radical absorbance capacity (ORAC) using a multichannel liquid handling system coupled with a microplate fluorescence reader in 96-well format. Journal of Agricultural and Food Chemistry. https://doi.org/10. 1021/jf0201529

10. Prior, R., Hoang, H., Gu, L., Wu, X., Bacchiocca, M., Howard, L., et al. (2003). Assays for hydrophilic and lipophilic antioxidant capacity (oxygen radical absorbance capacity $\left(\mathrm{ORAC}_{\mathrm{FL}}\right)$ ) of plasma and other biological and food samples. Journal of Agricultural and Food Chemistry. https://doi.org/10.1021/jf0262256

11. Benzie, I., \& Strain, J. (1996). The ferric reducing ability of plasma (FRAP) as a measure of "antioxidant power": the FRAP assay. Analytical Biochemistry. https://doi.org/10.1006/abio.1996. 0292

12. Cicco, N., Lanorte, M., Paraggio, M., Viggiano, M., \& Lattanzio, V. (2009). A reproducible, rapid and inexpensive Folin-Ciocalteu micro-method in determining phenolics of plant methanol extracts. Microchemical Journal. https://doi.org/10.1016/j.microc. 2008.08.011

13. Laine, J., Vasander, H., Hotanen, J.-P., Saarinen, M., \& Penttilä, T. (2012). Suotyypit ja turvekankaat - opas kasvupaikkojen tunnistamiseen (Mire Site Types - a Guide for Identification). Hämeenlinna, Finland: Metsäkustannus Ltd.

14. Vollmer, A., Belkin, S., Smulski, D., Van Dyk, T., \& LaRossa, R. (1997). Detection of DNA damage by use of Escherichia coli carrying recA'::lux, uvrA'::lux, or alkA'::lux reporter plasmids. Applied and Environmental Microbiology. https://doi.org/10. 1128/AEM.63.7.2566-2571.1997

15. Välimaa, A.-L., Raitanen, J.-E., Tienaho, J., Sarjala, T., Nakayama, E., Korpinen, R., et al. (2020). Enhancement of Norway spruce bark side-streams: Modification of bioactive and protective properties of stilbenoid-rich extracts by UVA-irradiation. Industrial Crops and Products. https://doi.org/10.1016/j.indcrop.2020. 112150

16. Tienaho, J., Karonen, M., Muilu-Mäkelä, R., Kaseva, J., de Pedro, N., Vicente, F., et al. (2020). Bioactive properties of the aqueous extracts of endophytic fungi associated with Scots Pine (Pinus sylvestris) Roots. Planta medica. https://doi.org/10. 1055/a-1185-4437

17. Chambers, J. M. (1996). Linear Models in Statistics. In J. M. Chambers \& T. J. Hastie (Eds.), Statistical Models in S. Michigan, USA: Wadsworth \& Brooks/Cole Advanced Books \& Software. 
18. R Core Team, R: A language and environment for statistical computing. R Foundation for Statistical Computing, Vienna, Austria, 2020. https://www.R-project.org/.

19. Kinnunen, H., Huttunen, S., \& Laakso, K. (2001). UV-absorbing compounds and waxes of Scots pine needles during a third growing season of supplemental UV-B. Environmental Pollution. https://doi.org/10.1016/S0269-7491(00)00113-5

20. J. M. Glime, in Bryophyte Ecology, ed. J. M. Glime, 2017, Chapter 9-3. Vol. 1. Physiological Ecology, ebook available in https:// digitalcommons.mtu.edu/bryophyte-ecology/.

21. Taskila, S., Särkelä, R., \& Tanskanen, J. (2016). Valuable applications for peat moss. Biomass Conversion and Biorefinery. https:// doi.org/10.1007/s13399-015-0169-3

22. Jassey, V., Gilbert, D., Binet, P., Toussaint, M.-L., \& Chiapusio, G. (2011). Effect of a temperature gradient on Sphagnum fallax and its associated living microbial communities: a study under controlled conditions. Canadian Journal of Microbiology. https:// doi.org/10.1139/W10-116

23. Jassey, V., Chiapusio, G., Mitchell, E., Binet, P., Toussaint, M.-L., \& Gilbert, D. (2011). Fine-scale horizontal and vertical micro-distribution patterns of testate amoebae along a narrow fen/bog gradient. Microbial Ecology. https://doi.org/10.1007/ s00248-010-9756-9

24. Jain, P. \& Bari, S. (2010). Isolation of Lupeol, Stigmasterol and Campesterol from Petroleum Ether Extract of Woody Stem of Wrightia tinctoria. Asian Journal of Plant Sciences. https://doi. org/https://doi.org/10.3923/ajps.2010.163.167
25. Sitorus, P., Harahap, U., Pandapotan, M., \& Barus, T. (2014). Isolation of $\beta$-sitosterol from n-hexane extract of Picria fel-terrae Lour. leave and study of its antidiabetic effect in alloxan induced diabetic mice. International Journal of PharmTech Research, 6, 137-141.

26. Naumova, G., Tomson, A., Zhmakova, N., Makarova, N., \& Ovchinnikova, T. (2013). Phenolic compounds of Sphagnum peat. Solid Fuel Chemistry. https://doi.org/10.3103/S03615219120600 92

27. Fudyma, J., Lyon, J., AminiTabrizi, J., Gieschen, H., Chu, R., Hoyt, D., et al. (2019). Untargeted metabolomic profiling of Sphagnum fallax reveals novel antimicrobial metabolites. Plant Direct. https://doi.org/10.1002/pld3.179

28. Snell, K., Kokubun, T., Griffiths, H., Convey, P., Hodgson, D., \& Newsham, K. (2009). Quantifying the metabolic cost to an Antarctic liverwort of responding to UV-B radiation exposure. Global Change Biology. https://doi.org/10.1111/j.1365-2486. 2009.01929.x

29. Waterman, M., Nugraha, A., Hendra, R., Ball, G., Robinson, S., \& Keller, P. (2017). Antarctic Moss Biflavonoids Show High Antioxidant and Ultraviolet-Screening Activity. Journal of Natural Products. https://doi.org/10.1021/acs.jnatprod.7b00085

30. Monforte, L., Soriano, G., Nunez-Olivera, E., \& Martinez-Abaigar, J. (2017). Cell compartmentation of ultraviolet-absorbing compounds: An underexplored tool related to bryophyte ecology, phylogeny and evolution. Functional Ecology. https://doi.org/10. $1111 / 1365-2435.13048$ 